\title{
Serotonin is required for pharyngeal arch morphogenesis in zebrafish
}

\author{
Saleh Bashammakh*, Martin Würtele, Katarina Kotnik, Salim Abdelilah-Seyfried, and Michael Bader \\ Max-Delbrück-Center for Molecular Medicine (MDC), Berlin, Germany \\ *Corresponding author's e-mail address: sbashammakh@hotmail.de
}

Published online: 22 December 2014 (version 1)

Cite as: Bashammakh et al. ScienceOpen Research 2015 (DOI: 10.14293/S2199-1006.1.SOR-LIFE.AWPDLZ.v1)

Reviewing status: Please note that this article is under continuous review. For the current reviewing status and the latest referee's comments please click here or scan the QR code at the end of this article.

Primary discipline: Life sciences

Keywords: Serotonin, Zebrafish, Pharyngeal arches, Neural crest cells

\begin{abstract}
Serotonin (5-HT) is not only a neurotransmitter but also a mediator of developmental processes in vertebrates. In this study, we analyzed the importance of 5-HT during zebrafish development. The expression patterns of three zebrafish tryptophan hydroxylase isoforms (Tph1A, Tph1B, Tph2), the rate-limiting enzymes in 5-HT synthesis, were analyzed and compared to the appearance and distribution of 5-HT. 5-HT was found in the raphe nuclei correlating with tph2 expression and in the pineal gland correlating with tph1a and tph2 expressions. Tph2-deficient fish generated with antisense morpholino oligonucleotides exhibited morphogenesis defects during pharyngeal arch development. The correct specification of neural crest (NC) cells was not affected in tph2 morphants as shown by the expression of early markers, but the survival and differentiation of pharyngeal arch progenitor cells were impaired. An organizing role of 5-HT in pharyngeal arch morphogenesis was suggested by a highly regular pattern of 5-HT positive cells in this tissue. Moreover, the 5-HT2B receptor was expressed in the pharyngeal arches and its pharmacological inhibition also induced defects in pharyngeal arch morphogenesis. These results support an important role of Tph2-derived serotonin as a morphogenetic factor in the development of NC-derived tissues.
\end{abstract}

\section{INTRODUCTION}

The pharyngeal arch cartilage in vertebrates is formed by neural crest (NC) cells. These cells arise from the border between the neural ectoderm forming the neural tube and the non-neural ectoderm forming the epidermis [1]. They migrate throughout the body to yield a wide range of different tissues, like the peripheral nervous system, the chromaffin cells of the adrenal medulla, the pharyngeal arches, melanocytes and others [2]. The cranial NC cells migrate from the hindbrain in three streams, trigeminal, hyoid, and postotic, which can be identified in the developing head of all vertebrate embryos and are essential for the development of the craniofacial region and the heart [3].
At the time when NC cells are migrating, the specification of neurons, which produce the neurotransmitter serotonin (5hydroxytryptamine, 5-HT), occurs in the mantle layer of the hindbrain induced by the signaling proteins sonic hedgehog (SHH) and fibroblast growth factor 8 (FGF8) released by the floor plate and midbrain-hindbrain boundary, respectively [4]. Mutants of shh in zebrafish do not develop 5-HT neurons and also show the near complete absence of the NC-derived craniofacial skeletal elements $[5,6]$. The same defects in specification of 5-HT neurons and the NC-derived craniofacial elements were observed in the zebrafish mutants of $f g f 8$ $[5,7]$. Analysis of NC cell development in $f g f 8$ mutant embryos demonstrated that these cells are specified and migrate, but undergo cell death [8]. These observations raised the intriguing possibility that the availability of 5-HT to NC cells may be a common denominator of craniofacial defects in both $f g f 8$ - and shh-deficient animals.

5 -HT is not only a neurotransmitter but mounting evidence suggests that it also plays a role in early development and morphogenesis of both invertebrates and vertebrates. It was shown to be pivotal for the first embryonic cell divisions in several classes of invertebrates $[9,10]$. In vertebrates, 5 -HT has been detected in preimplantation embryos and in embryonic stem cells $[11,12]$. It controls cell proliferation and is essential for left-right symmetry establishment in vertebrate embryos and for the survival, the migration and differentiation of mouse cranial NC cells in embryo culture [13-20]. However, mechanistic explanations for 5-HT functions within non-neuronal cell types are largely missing.

The rate-limiting step for the synthesis of 5-HT is catalyzed by tryptophan hydroxylase (Tph) that hydroxylates tryptophan generating 5-hydroxytryptophan. This metabolite is decarboxylated by aromatic amino acid decarboxylase to 5-HT. In mammals there are two different Tph enzymes, Tph1 and Tph2, active mutually exclusively in the periphery and in the brain, respectively $[21,22]$. In the zebrafish, till now three genes of Tph, tph1a (or tphD1), tph1b (or tphD2), and tph2 (or $t p h R$ ) were cloned by us (GenBank: AY616135 and 
AY616134) and others [5, 23]. Most likely, this increase in tph gene number is due to teleost genome duplication during evolution [24], and the postulated fourth tph gene probably got lost afterwards.

Serotonin is taken up into cells by the specific serotonin transporter (SERT) followed either by storage into vesicles through the vesicular monoamine transporters (VMAT) 1 or 2 or by degradation catalyzed by monoamine oxidases (MAO) A or $\mathrm{B}$ on mitochondria. In addition, the pineal gland synthesizes 5-HT and metabolizes it further to melatonin.

5-HT interacts with at least 14 different receptors grouped in 7 families, 5-HT1 to 5-HT7 [25]. The rodent 5-HT2B receptor is expressed in NC cells and in the pharyngeal arches [16, 26]. In vitro studies in mouse embryo cultures [14, 26] and a recent in vivo study in Xenopus embryos [27] showed that altered expression of the 5-HT2B receptor or its pharmacological inhibition causes malformations of craniofacial tissues. In this study, we investigated the role of Tph1a, Tph2, 5-HT, and the 5-HT2B receptor during the development of the pharyngeal arches in the zebrafish.

\section{MATERIALS AND METHODS Animals}

Zebrafish lines were maintained in the $A B$ and WIK background, and fed and kept according to standard conditions [28]. Embryos were staged by hours post-fertilization (hpf) and days post-fertilization (dpf) at $28.5^{\circ} \mathrm{C}$ [29].

To block the action of 5-HT2B receptors, embryos were exposed to the specific 5-HT2 receptor antagonist ritanserin (Sigma-Aldrich, Munich, Germany) by addition to egg water at a concentration of $20 \mu \mathrm{M}$.

\section{Measurement of 5-HT}

A total of 10 zebrafish embryos of different stages were dechorionated, deyolked, and placed into a pre-cooled $\left(4^{\circ} \mathrm{C}\right)$ Eppendorf tube containing $30 \mu \mathrm{l}$ of a mixure of $50 \mathrm{mM}$ tris-acetate buffer $\mathrm{pH} 7.5,5 \mathrm{mM}$ sodium metabisulfite, and $10 \mathrm{mM}$ ascorbic acid as antioxidants and homogenized $30 \mathrm{~s}$. by ultrasound. The protein was precipitated by addition of $100 \mathrm{mM}$ perchloric acid, vortexed for $10 \mathrm{~s}$, and centrifuged at $4^{\circ} \mathrm{C}, 17,000 \times \mathrm{g}$ for 25 minutes. The supernatant was transferred to a new pre-cooled tube. 5-HT measurements were performed using HPLC with fluorimetric detection as described [30].

\section{Reverse transcription polymerase chain reaction}

Total RNA was isolated from different stages of zebrafish embryos (8-cell, blastula, gastrula, $1 \mathrm{dpf}$, and $2 \mathrm{dpf}$ stages) using TRIZOL (Invitrogen). The corresponding cDNAs were prepared using the reverse transcriptase reaction kit according to the instructions of the manufacturer (Promega, Mannheim, Germany). Expression of Tph2 and the housekeeping gene $\beta$-actin 1 was detected by polymerase chain reaction (PCR) using the specific primers:

Tph2 forward, 5'-GTAAGGCCTGTGGCTGGATA-3'

Tph2 reverse, $5^{\prime}$-ATCTTCGTCTGAAGCGCCTA-3'

$\beta$-actin1 forward, 5'-GCTCTCTTCCAGCCTTCCTT-3'

$\beta$-actin1 reverse, $5^{\prime}$-CATTGTGAGGAGGGCAAAGT-3'

\section{Alcian blue staining}

For skeletal analysis, larvae were fixed in 4\% paraformaldehyde and transferred into a $0.1 \%$ solution of alcian blue dissolved in $80 \%$ ethanol $/ 20 \%$ acetic acid. After staining in this solution overnight, embryos were rinsed in ethanol and rehydrated gradually into PBS. Pigmentation was then removed by bleaching in $3 \%$ hydrogen peroxide/1\% potassium hydroxide.

\section{Immunohistochemistry}

Zebrafish embryos were dechorionated, fixed in $4 \%$ paraformaldehyde, permeabilized with $0.1 \%$ collagenase for 30 minutes and incubated with the primary antibody (rabbit anti-5-HT, diluted 1:500 (Sigma), or rabbit anti-Foxd3, diluted 1:400) [31] followed by incubation with the secondary antibody, anti-rabbit-Cy3, diluted 1:1000 (Sigma). Whole embryos were documented under a Leica MZFLIII stereomicroscope using the $1 \times$ and $4 \times$ objectives with $5-10 \times$ zoom and Leica IM50 software package. Photos were processed using Photoshop (Adobe).

\section{Cloning of Danio rerio cDNA for Tph1B, Tph2, and 5-HT2B}

The zebrafish database was screened with sequences from the conserved domains of corresponding mammalian genes and homologues of Tph and the 5-HT2B receptor (HTR2B) were identified. Full-length cDNAs were amplified from RNA extracted from adult fish by reverse transcription polymerase chain reaction (RT-PCR), sequenced and deposited to GenBank (tph1b: AY616135, tph2: AY616134, htr2b: DQ864496).

\section{Whole-mount in situ hybridization}

For in situ hybridization, antisense riboprobes for the following genes were used: tph1a (AF548566), tph1b (AY616135), tph2 (AY616134), sox9b (AY627769), crestin (AF195881), tfap2a (NM_176859), dlx2a (NM_131311), sox9a (NM_ 131643), and 5-htr2b (DQ864496). The cDNA fragments (300-600 bp long) were obtained by RT-PCR and subcloned into the pGEM-T or pGEM-T Easy vector (Promega). Purified plasmids were linearized, and in vitro transcription was performed with T7 or SP6 RNA polymerase, in the presence of digoxigenin (dig)-UTP (Roche). Whole-mount in situ hybridizations were performed as described by Akimenko et al. [32]. 


\section{Injections of mRNA and antisense morpholino oligonucleotides}

The following antisense-oligonucleotide morpholinos (MO) were ordered from GeneTools (Philomath, OR, USA) and injected into the yolk of one-cell embryos at the concentration of $100-150 \mu \mathrm{M}$.

tph1a 5UTR: 5'-TTGCTGATGTATAAACACGCCCTGG tph2 ATG: 5'-GAACATCATCATGGCAGGTTGCATC

foxd3 5UTR: 5'-TGCTGCTGGAGCAACCCAAGGTAAG

For the rescue experiment, full length tph2 cDNA was subcloned into the pCS2 expression vector. The construct was linearized with ApaI, in vitro transcribed with SP6 RNA polymerase using MESSAGE MACHINE kit (Ambion), and $50 \mathrm{pg}$ mRNA were injected into 1- to 4-cell stage zebrafish embryos together with tph2 MO.

\section{RESULTS AND DISCUSSION 5-HT and Tph isoforms in zebrafish embryos}

5-HT was detected by HPLC in whole zebrafish embryos at different early stages of development starting from 8-cell, blastula, gastrula, $1 \mathrm{dpf}$, and $2 \mathrm{dpf}$ stages (Figure 1A). The expression of tph1a (not shown) and tph2 could be detected by RT-PCR in whole zebrafish embryos of the gastrula, $1 \mathrm{dpf}$, and $2 \mathrm{dpf}$ stages but hardly before (Figure 1B). Probably, the decreasing 5-HT levels from 8-cell to gastrula stages are of a maternal origin and the embryonic production of 5-HT starts after the gastrula stage as shown by tph2 expression. By in situ hybridization, tph1a mRNA was detected at $24 \mathrm{hpf}$ in the pineal gland, where it persists at least until $6 \mathrm{dpf}$ (Figure 1C). This correlated with 5-HT immunoreactivity in this organ (Figure 1F). Tph2 expression appeared at $36 \mathrm{hpf}$ in bilateral longitudinal columns in the anterior hindbrain (Figure 1D, E), which correspond to raphe neurons as shown by 5 -HT immunoreactivity (Figure 1F). In contrast to mammals [21], tph2 mRNA can also be detected in the pineal gland of zebrafish larvae (Figure 1D). We could not detect tph1b expression at any embryonic stage tested. These findings corresponded to published data except for tph1b which was reported to be expressed in the preoptic area of the ventral diencephalon for a short time period in development $[23,33]$. In addition to the pineal gland and the hindbrain (Figure 1F), 5-HT positive cells, were detected in the developing pharyngeal arches of 3 $\mathrm{dpf}$ and $5 \mathrm{dpf}$ embryos (Figure 2G, H). Furthermore, 5-HT was found in single cells in the skin of the zebrafish larvae (Figure 1F-H), which are probably the chemoreceptors described by Jonz and Nurse [34].

\section{Phenotype of tph morphants}

Tissue-specific 5-HT depletion in tph morphants

To study the role of the two major Tph isoforms in zebrafish embryogenesis, we performed morpholino antisense oligonucleotide (M0)-mediated knockdown of tph1a and tph2. The resulting phenotypes were monitored until 6 dpf. Tph2 morphants had reduced levels of 5-HT in the hindbrain and in the pineal gland till $4 \mathrm{dpf}$ (Figure $1 \mathrm{H}$ ). Also a significant reduction in 5-HT positive cells was observed in the pharyngeal arches at $5 \mathrm{dpf}$ (Figure 2J). Fish injected with $\mathrm{MO}^{\text {tph1a }}$ showed reduction of 5-HT signals specifically in the pineal gland (Figure 1G) but not in the brainstem (Figure 1G) or the pharyngeal arches (Figure 2I).

Pharyngeal arch defects in tph2 morphants

Based on the obviously abnormal structure of tph2 morphant's jaws, we analyzed the role of Tph2 in the development of craniofacial tissue. Larvae injected with $\mathrm{MO}^{\text {tph2 }}$ showed greatly reduced cartilage in the pharyngeal arches compared with uninjected controls or those injected with $\mathrm{MO}^{\text {tph1a }}$ as based on alcian blue staining (Figure 2). Specifically, all five posterior pharyngeal arches (ceratobranchials and basibranchials) were absent in the tph2 morphants. In the second arch, the ceratohyal cartilage was strongly reduced. This arch was abnormally developed, being shorter and bent ventrally. The same orientation defect was observed in Meckel's cartilage in the first arch, the mandibular arch. There were no other abnormalities neither in the development of the upper jaw nor of the neurocranium visible in the tph2 morphants. tph2 mRNA, when co-injected with the $\mathrm{MO}^{t p h 2}$, rescued the phenotype indicating that the craniofacial defects were specifically caused by the knockdown of tph2 expression (Figure 2C).

NC cell specification and migration in tph2 morphants

The phenotype of tph2 morphants suggested that Tph2 depletion primarily affected NC cells which contribute to the craniofacial tissue. Therefore, we examined if Tph2 was involved in the establishment of NC identity by analyzing the expression of early NC markers using in situ hybridization or immunohistochemistry at different developmental stages ( 5 and 25 somites). However, expression of FoxD3, sox $9 b$, tfap $2 a$, and crestin remained unaffected in tph2 morphants in comparison to uninjected control embryos (Figure 3 and data not shown). We assessed cranial NC cell migration using the marker $d l \times 2 a$ during different stages (24, 30 and 36 hpf) in tph2 morphants. $d l \times 2 a$ expression was reduced in the third NC cell streams at $24 \mathrm{hpf}$ stage and this reduction remained until 30 hpf and 36 hpf in tph2 morphants (Figure 3). In some cases we observed a fusion of the first and second stream (Figure 3). How does the lack of Tph2 influence NC cell migration or survival? Embryonic 5-HT and Tph2 expression starts from gastrula stage onwards, already before NC cell specification and migration (Figure 1A, B). Wang et al. [35] and Airhart et al. [36] observed 5-HT and Tph2 expression in the brain at $24 \mathrm{hpf}$ and Lillesaar et al. [37] at 30 and $36 \mathrm{hpf}$ in the hindbrain, which corresponds with the time when cranial NC cells migrate [38]. Low concentrations of 5-HT have been found to stimulate migration of mouse NC cells in culture, while high levels of 5-HT have no effect $[18,20]$. Thus, NC cell migration may be oriented by the gradient of 5-HT, which develops from the serotonergic cells in the hindbrain via their 5-HT1A 
A
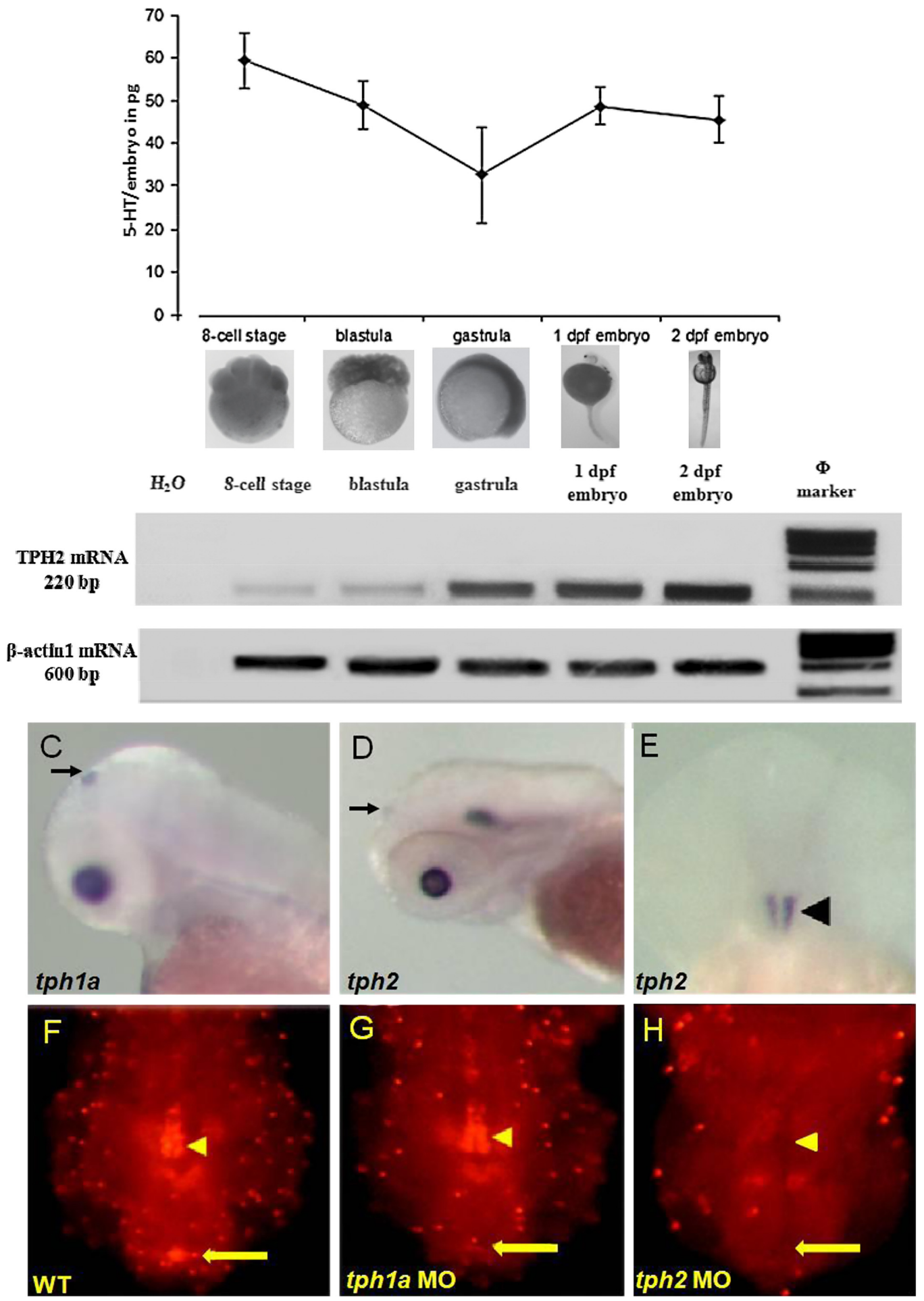

Figure 1. 5-HT and Tph2 expression in embryonic stages of zebrafish. 5-HT levels decrease from 8-cell- to gastrula stages and start to increase again after the gastrula stage in $1 \mathrm{dpf}-$, and $2 \mathrm{dpf}$ stages (A). tph2 mRNA could be detected by RT-PCR in increasing concentrations during early development (B). In situ hybridization of $2 \mathrm{dpf}$ embryos with riboprobes for tph1a (C) and tph2 (lateral view, (D) and dorsal view, (E)) revealed tph1a expression in pineal gland (arrow) (C) and tph2 expression in pineal gland (arrow) and hindbrain (arrow head) (D,E). 5-HT staining in $2 \mathrm{dpf}$ embryos (dorsal view). Wild type (F); tph1a morphants (G); tph2 morphants (H). In comparison to the wild type, tph1a morphants exhibit a reduction in the 5-HT signal only in the pineal gland (arrows), while tph2 morphants show a reduction in 5-HT signals in the pineal gland (arrows) and in the hindbrain (arrow heads). 

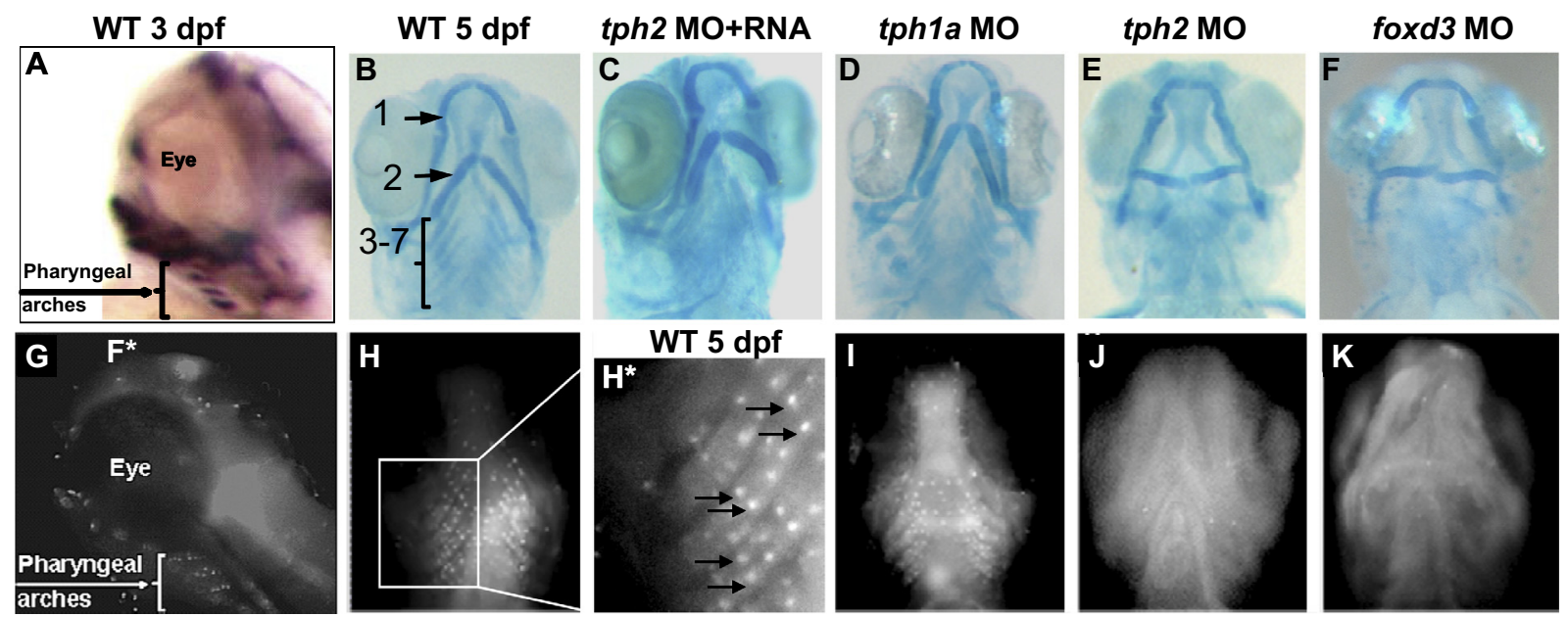

Figure 2. Pharyngeal arches in tph2 and foxd3 morphants: Ventral view of pharyngeal arches of 5 dpf embryos stained by alcian blue (B-F) and 5-HT immunohistochemistry (H-K). Wild type (A,B,G,H), tph1a morphants (D,I), tph2 morphants (E,J), and foxd3 morphants $(\mathrm{F}, \mathrm{K})$. Pharyngeal arch defects in tph2 morphants could be rescued by tph2 mRNA coinjection (C). Individual pharyngeal arches are indicated in (B): (1) mandibular arch; (2) hyoid arch; (3-7) posterior arches. ( $H^{*}$ ) Closer view on pairs of 5-HT positive cells. (A,G) Lateral view of $3 \mathrm{dpf}$ embryos stained for $5-\mathrm{HT}(\mathrm{G})$ and by in situ hybridisation for sox9a (A). Serotonin co-localizes in the pharyngeal arches with differentiated NC cells marked by sox9a.

receptors which are already expressed in $24 \mathrm{hpf}$ zebrafish embryos [20, 36]. Furthermore, the 5-HT2B receptor has been shown to convey a survival signal for NC cells [16]. This may explain the reduction of the cranial NC cell streams in tph2 morphants (Figure 3). Accordingly, it has been postulated that the observed lack of NC cells close to rhombomeres r3 and r5 in mice is due to 5-HT depletion by the locally expressed SERT [16].

NC markers and 5-HT positive cells in pharyngeal arches

It was reported, that knockdown of the early $\mathrm{NC}$ marker foxd3 also results in defects in the pharyngeal arches [31]. In order to check whether foxd3 is upstream or downstream of Tph2 in NC development, we generated foxd3 morphants. At $2 \mathrm{dpf}$, foxd3 morphants still exhibit 5-HT immunostaining in hindbrain and pineal gland (data not shown). However, at 5 dpf, alcian blue staining revealed defects in the pharyngeal arches similar to the ones in tph2 morphants (Figure 2F). Moreover, foxd3 morphants lack 5-HT positive cells in this tissue (Figure $2 \mathrm{~K}$ ) indicating that the development of these cells is dependent on the NC marker foxd3.

In $3 \mathrm{dpf}$ embryos, when we detected the 5-HT positive cells in the pharyngeal arches (Figure 2G), we could also observe the expression of $\operatorname{sox} 9 a$ in this tissue (Figure 2A). sox $9 a$ is a marker for NC cells during their differentiation into cartilage cells. Comparison of Figure 2A, G revealed a similar distribution pattern of 5-HT and sox $9 a$ positive cells, suggesting close proximity or even identity of these cells. Intriguingly, these cells are very regularly spaced and form pairs within the pharyngeal arches (Figure $2 \mathrm{H}$ ). Our results show that the depletion of Tph2 causes a severe reduction of these cells which coincides with defective morphogenesis of this tissue.
Because tph2 is apparently not expressed by these cells, 5-HT is most likely taken up in a paracrine fashion and enriched within this subset of NC cells. Cranial NC cells express SERT [39] and the importance of serotonin uptake for cranial NC development is underscored by the findings that SERT inhibitors such as fluoxetine and sertraline, cause craniofacial malformations in cultured mouse embryos [40]. Furthermore, high 5-HT transport activity [41], and marked expression of VMAT1 [42] and MAOB [43] have been reported in pharyngeal arches of mouse embryos confirming the need for efficient serotonin sequestration and degradation in this tissue. SERT on so-called "instructor" cells has been implicated in reducing 5-HT levels in the surrounding skin tissue, thereby stopping the migration of another type of NC-derived cells, melanocytes [44]. However, what determines the regular saltand pepper-like pattern of 5-HT enriched cells in pharyngeal arches and whether they have an analogous function as these "instructor" cells, remains currently unknown. These cells were discussed to form the Merkel-like basal cells of taste buds $[45,46]$. The taste buds contain different cell types and the pharyngeal endoderm is the origin of calb2b positive taste receptor cells but not of 5-HT positive Merkel-like basal cells. The development of the latter cells depends on ascl1 and Fgf signaling [45] which are also involved in TPH2 positive neuron development $[4,5]$. Moreover the blockage of Fgf signaling also caused pharyngeal arch defects in zebrafish [45]. Therefore, we think that the 5-HT positive cells, which may play an important role in pharyngeal arch morphogenesis, are derived from NC cells and the source of 5-HT in these cells is dependent on Tph2 activity. This observation raises several important issues including the question, why tph2 knockout 


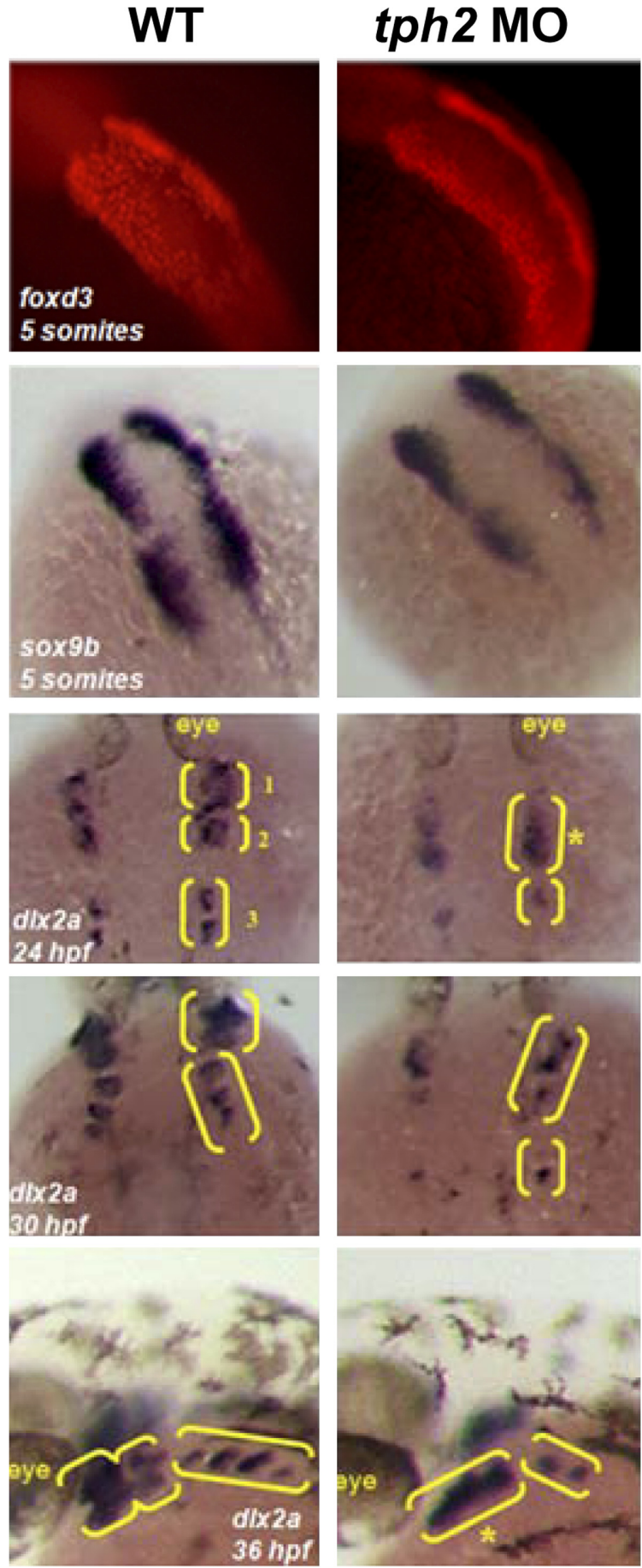

Figure 3. Neural crest induction and migration: Dorsal view of zebrafish embryos (left: wild type (WT) and right: tph2 morphants (tph2 MO)) at different stages showing expression of early NC markers sox $9 b, d l \times 2 a$ (in situ hybridisation), and foxd3 (immunostaining). No differences were detected in the expression of early NC cell markers (sox9b and foxd3) between tph2 $\mathrm{MO}$ and WT embryos. A reduction in the third migrating cranial NC cell streams (brackets) was observed in tph2 MO. * shows the fusion of the first and the second stream sometimes observed in tph2 $\mathrm{MO}$. mice [47] exhibit no obvious craniofacial abnormalities (Alenina et al., unpublished observations). This lack of NC phenotype may be due to serotonin transferred from the mother to the fetus in mammals $[48,49]$, which is not available in egg-laying vertebrates such as fish.

Role of 5-HT2B receptor in pharyngeal arch development

Next, we investigated which 5 -HT receptor(s) are involved in the actions of 5-HT on NC cells. The 5-HT2B receptor has been shown to participate in craniofacial and cardiac morphogenetic events in mice and Xenopus [16, 26, 27] and was, therefore, a valid candidate. Furthermore, it is known that this receptor regulates the activity of SERT [50]. We cloned the only zebrafish 5 -HT2B receptor gene by its homology to the mammalian counterpart and studied its expression pattern and function. The htr2b gene DQ864496 is located on chromosome 22, and contains 3 exons and 2 introns like in all other vertebrates. Its expression can be detected at $2 \mathrm{dpf}$ embryos in the heart and in the post-migration cranial NC cells that differentiate to the mandibular and hyoid arches (Figure 4A). In $3 \mathrm{dpf}$ embryos the expression becomes restricted to the mandibular arches and persists at least until 4 dpf (Figure 4B).

Ritanserin is a specific 5-HT2 receptor antagonist with specificity for the 5-HT2B receptor [10]. In fish embryos exposed to ritanserin from the blastula stage until $5 \mathrm{dpf}$, we detected craniofacial malformations (Figure 4D), comparable but less pronounced than in tph2 morphants. The defects were restricted to the mandibular and hyoid arches. Their structures were smaller in size and misshaped. Furthermore, they were oriented more downward in comparison to the posterior branchial arches, which were not markedly affected by ritanserin.

To follow the temporal effect of ritanserin in pharyngeal arch development, we treated embryos for 24-hour intervals between $4-24,24-48,48-72,72-96$, and 96-120 hpf. The analysis revealed an effect of ritanserin between 48 and 120 hpf, which was comparable to the pharyngeal arch defects in embryos exposed to ritanserin from blastula stage to $5 \mathrm{dpf}$ (data not shown). These data show that the 5-HT2B receptor plays an essential role after NC migration und during their differentiation in the pharyngeal arches. Accordingly, defects in heart morphology which may be also due to abnormal NC development have been described for mice deficient in 5HT2B receptors [51].

Reisoli et al. [27, 52] have also shown that in Xenopus embryos 5-HT2B receptors on NC cells are required for the shaping of branchial arches and jaw joint formation but not prior to or during their migratory phase. Our data together with these findings and the observations in mouse embryo cultures clearly demonstrate that serotonin is essential for NC-dependent development of craniofacial structures in vertebrates. The exact role of serotonin, its transporter and its receptors in the cellular interactions shaping the jaws still remains elusive. A possible scenario could be that upon 

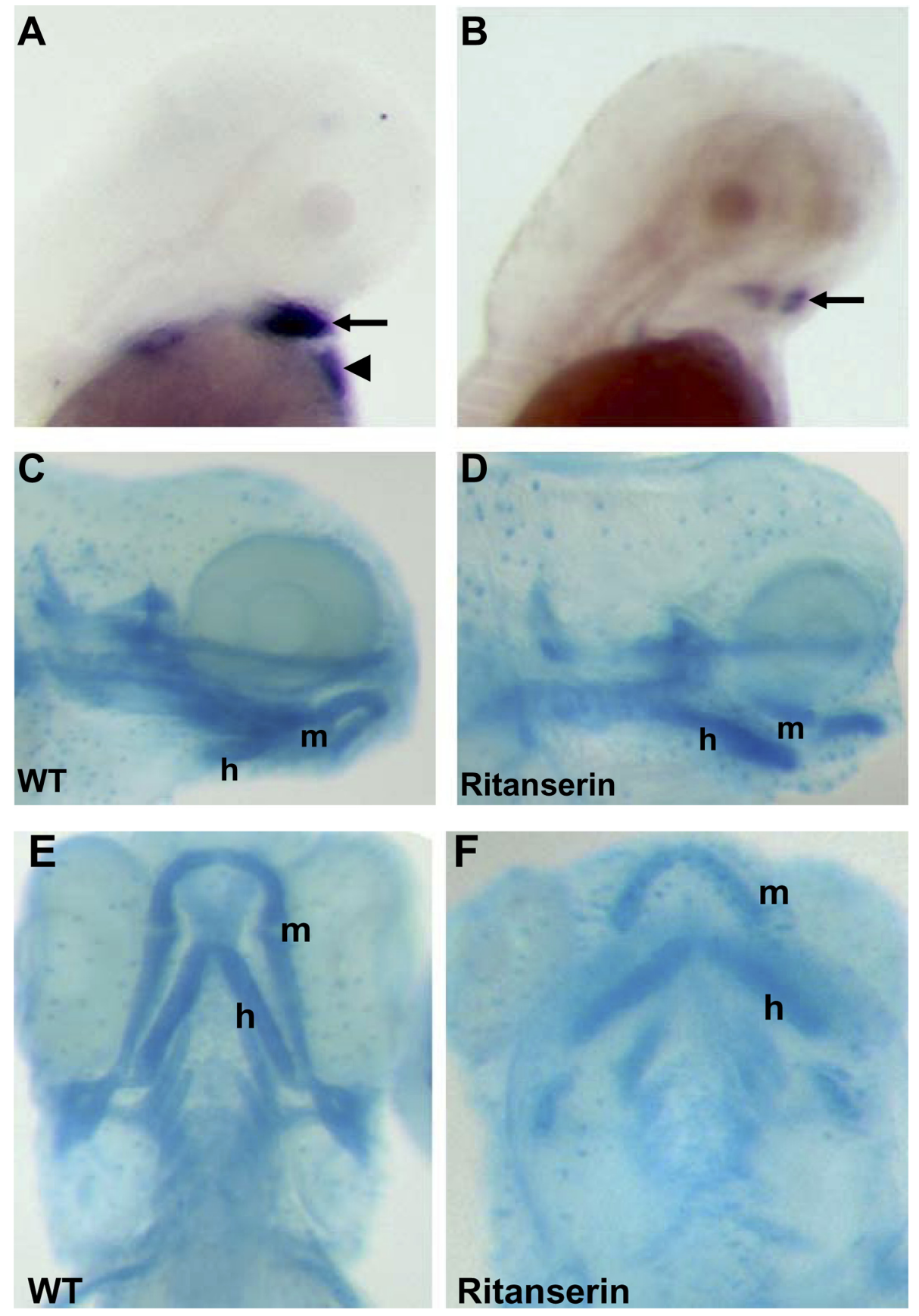

Figure 4. 5-HT2B receptor in pharyngeal arches. In situ hybridization of 2 (A) and $3 \mathrm{dpf}(\mathrm{B})$ zebrafish embryos with a htr2b riboprobe (lateral view). The 5-HT2B receptor is expressed in $2 \mathrm{dpf}$ in the heart (arrowhead) and in the post-migration cranial NC cells that differentiate to the mandibular and hyoid arches (arrow) (A). In 3 dpf embryos the expression becomes restricted to the mandibular arch (arrow) (B). Alcian blue staining of pharyngeal arches of untreated 5 dpf zebrafish embryos (lateral view $\mathrm{C}$, ventral view $\mathrm{E}$ ) and treated with ritanserin from $4 \mathrm{hpf}$ onwards (lateral view D, ventral view F). The mandibular $(\mathrm{m})$ and hyoid (h) arches of ritanserin treated embryos were mis-shaped and oriented more ventrally in comparison to controls.

arrival at the pharyngeal arches a subset of NC cells expresses SERT under the control of the 5-HT2B receptor and removes serotonin from the surrounding tissue, which in turn stops the migration of NC cells and induces their differentiation. In this study, we provide evidence that the enzyme responsible for the synthesis of the serotonin involved in these processes is Tph2.

Interestingly, the duplication of the TPH genes, and the appearance of Raphe nuclei coincides with the development of jaws in evolution. Jawless fish (agnatha) like lamprey have 
only one TPH gene (GI:359719324) and no Raphe nuclei [53], and most jawed fish (gnathostomes) like Elephant shark, have Raphe nuclei [54] and two TPH genes (http://esharkgenome.imcb.a-star.edu.sg) (Tph1, GI:632940917; Tph2, GI:632970997). Thus, there is supporting evidence from evolution that Tph2 and the development of jaws are linked.

\section{ACKNOWLEDGMENTS}

We acknowledge Adelheid Böttger, Marleen Klann, and Cathrin Rudolph for excellent technical assistance and Dr. Stefan Rohr for the scientific discussions and Dr. Natalia Alenina for critical reading of the manuscript.

\section{REFERENCES}

[1] Bronner ME, Ledouarin NM. Development and evolution of the neural crest: an overview. Dev Biol. 2012;366:2-9. doi:10.1016/ j.ydbio.2011.12.042.

[2] Sauka-Spengler T, Bronner-Fraser, M. A gene regulatory network orchestrates neural crest formation. Nat Rev Mol Cell Biol. 2008;9:557-68. doi:10.1038/nrm2428.

[3] Graham A, Begbie J, McGonnell I. Significance of the cranial neural crest. Dev Dyn. 2004;229:5-13. doi:10.1002/dvdy.10442

[4] Alenina N, Bashammakh S, Bader M. Specification and differentiation of serotonergic neurons. Stem Cell Rev. 2006;2:5-10. doi:10.1007/s12015-006-0002-2

[5] Teraoka H, Russell C, Regan J, Chandrasekhar A, Concha ML, Yokoyama R, Higashi K, Take-Uchi M, Dong W, Hiraga T, Holder $\mathrm{N}$, Wilson SW. Hedgehog and Fgf signaling pathways regulate the development of tphR-expressing serotonergic raphe neurons in zebrafish embryos. J Neurobiol. 2004;60:275-88. doi:10.1002/neu.20023

[6] Wada N, Javidan Y, Nelson S, Carney TJ, Kelsh RN, Schilling TF. Hedgehog signaling is required for cranial neural crest morphogenesis and chondrogenesis at the midline in the zebrafish skull. Development. 2005;132:3977-88. doi:10.1242/dev. 01943

[7] Albertson RC, Yelick PC. Roles for fgf8 signaling in left-right patterning of the visceral organs and craniofacial skeleton. Dev Biol. 2005;283:310-21. doi:10.1016/j.ydbio.2005.04.025

[8] Abu-Issa R, Smyth G, Smoak I, Yamamura K, Meyers EN. Fgf8 is required for pharyngeal arch and cardiovascular development in the mouse. Development. 2002;129:4613-25.

[9] Buznikov GA, Lambert HW, Lauder JM. Serotonin and serotoninlike substances as regulators of early embryogenesis and morphogenesis. Cell Tissue Res. 2001;305:177-86. doi:10.1007/ s004410100408

[10] Buznikov GA, Peterson RE, Nikitina LA, Bezuglov VV, Lauder JM. The pre-nervous serotonergic system of developing sea urchin embryos and larvae: pharmacologic and immunocytochemical evidence. Neurochem Res. 2005;30:825-37. doi:10.1007/ s11064-005-6876-6

[11] Basu B, Desai R, Balaji J, Chaerkady R, Sriram V, Maiti S, Panicker MM. Serotonin in pre-implantation mouse embryos is localized to the mitochondria and can modulate mitochondrial potential. Reproduction. 2008;135:657-69. doi:10.1530/REP07-0577

[12] Walther DJ, Bader M. Serotonin synthesis in murine embryonic stem cells. Brain Res Mol Brain Res. 1999;68:55-63. doi:10.1016/S0169-328X(99)00046-7

[13] Beyer T, Danilchik M, Thumberger T, Vick P, Tisler M, Schneider I, Bogusch S, Andre P, Ulmer B, Walentek P, Niesler B, Blum M, Schweickert A. Serotonin signaling is required for Wnt-dependent
GRP specification and leftward flow in Xenopus. Curr Biol. 2012; 22:33-39. doi:10.1016/j.cub.2011.11.027

[14] Bhasin N, Kernick E, Luo X, Seidel HE, Weiss ER, Lauder JM. Differential regulation of chondrogenic differentiation by the serotonin2B receptor and retinoic acid in the embryonic mouse hindlimb. Dev Dyn. 2004;230:201-9. doi:10.1002/dvdy.20038

[15] Bhasin N, LaMantia AS, Lauder JM. Opposing regulation of cell proliferation by retinoic acid and the serotonin2B receptor in the mouse frontonasal mass. Anat Embryol (Berl). 2004; 208:135-43. doi:10.1007/s00429-004-0380-7

[16] Choi DS, Ward SJ, Messaddeq N, Launay JM, Maroteaux L. 5-HT2B receptor-mediated serotonin morphogenetic functions in mouse cranial neural crest and myocardiac cells. Development. 1997;124:1745-55.

[17] Fukumoto T, Kema IP, Levin M. Serotonin signaling is a very early step in patterning of the left-right axis in chick and frog embryos. Curr Biol. 2005;15:794-803. doi:10.1016/j.cub.2005. 03.044

[18] Kawakami M, Umeda M, Nakagata N, Takeo T, Yamamura K. Novel migrating mouse neural crest cell assay system utilizing P0-Cre/EGFP fluorescent time-lapse imaging. BMC Dev Biol. 2011;11:68. doi:10.1186/1471-213X-11-68.

[19] Moiseiwitsch JR. The role of serotonin and neurotransmitters during craniofacial development. Crit Rev Oral Biol Med. 2000;11:230-9. doi:10.1177/10454411000110020601

[20] Moiseiwitsch JR, Lauder JM. Serotonin regulates mouse cranial neural crest migration. Proc Natl Acad Sci USA. 1995;92:71826. doi:10.1073/pnas.92.16.7182

[21] Walther DJ, Bader M. A unique central tryptophan hydroxylase isoform. Biochem Pharmacol. 2003;66:1673-80. doi:10.1016/ S0006-2952(03)00556-2

[22] Walther DJ, Peter JU, Bashammakh S, Hortnagl H, Voits M, Fink H, Bader M. Synthesis of serotonin by a second tryptophan hydroxylase isoform. Science. 2003;299:76.

[23] Bellipanni G, Rink E, Bally-Cuif L. Cloning of two tryptophan hydroxylase genes expressed in the diencephalon of the developing zebrafish brain. Mech Dev. 2002;119:S215-20. doi:10. 1016/S0925-4773(03)00119-9

[24] Amores A, Force A, Yan YL, Joly L, Amemiya C, Fritz A, Ho RK, Langeland J, Prince V, Wang Y-L, Westerfield M, Ekker M, Postlethwait JH Zebrafish hox clusters and vertebrate genome evolution. Science. 1998;282:1711-4. doi:10.1126/science.282. 5394.1711

[25] Filip M, Bader M. Overview on 5-HT receptors and their role in physiology and pathology of the central nervous system. Pharmacol Rep. 2009;61:761-77. doi:10.1016/S1734-1140(09) 70132-X

[26] Lauder JM, Wilkie MB, Wu C, Singh S. Expression of 5-HT(2A), 5-HT(2B) and 5-HT(2C) receptors in the mouse embryo. Int J Dev Neurosci. 2000;18:653-62. doi:10.1016/S0736-5748(00) 00032-0

[27] Reisoli E, De Lucchini S, Nardi I, Ori M. Serotonin 2B receptor signaling is required for craniofacial morphogenesis and jaw joint formation in Xenopus. Development. 2010;137:2927-37. doi:10.1242/dev.041079.

[28] Westerfield M. The Zebrafish book. A guide for the laboratory use of Zebrafish (Danio rerio) Eugene. Oregon: University of Oregon Press; 2007.

[29] Kimmel CB, Ballard WW, Kimmel SR, Ullmann B, Schilling TF. Stages of embryonic development of the zebrafish. Dev Dyn. 1995;203:253-310. doi:10.1002/aja.1002030302

[30] Tenner K, Qadri F, Bert B, Voigt JP, Bader M. The mTPH2 C1473G single nucleotide polymorphism is not responsible for behavioural differences between mouse strains. Neurosci Lett. 2008;431:21-5. doi:10.1016/j.neulet.2007.11.012 
[31] Lister JA, Cooper C, Nguyen K, Modrell M, Grant K, Raible DW. Zebrafish Foxd3 is required for development of a subset of neural crest derivatives. Dev Biol. 2006;290:92-104. doi:10.1016/j.ydbio.2005.11.014

[32] Akimenko MA, Ekker M, Wegner J, Lin W, Westerfield M. Combinatorial expression of three zebrafish genes related to distal-less: part of a homeobox gene code for the head. J Neurosci. 1994;14:3475-86.

[33] Lillesaar C. The serotonergic system in fish. J Chem Neuroanat. 2011;41:294-308. doi:10.1016/j.jchemneu.2011.05.009.

[34] Jonz MG, Nurse CA. Ontogenesis of oxygen chemoreception in aquatic vertebrates. Respir Physiol Neurobiol. 2006;154:13952. doi:10.1016/j.resp.2006.01.004

[35] Wang Y, Takai R, Yoshioka H, Shirabe K. Characterization and expression of serotonin transporter genes in zebrafish. Tohoku J Exp Med. 2006;208:267-74. doi:10.1620/tjem.208.267

[36] Airhart MJ, Lee DH, Wilson TD, Miller BE, Miller MN, Skalko RG, Monaco PJ. Adverse effects of serotonin depletion in developing zebrafish. Neurotoxicol Teratol. 2012;34:152-60. doi:10.1016/j. ntt.2011.08.008

[37] Lillesaar C, Tannhäuser B, Stigloher C, Kremmer E, Bally-Cuif L. The serotonergic phenotype is acquired by converging genetic mechanisms within the zebrafish central nervous system. Dev Dyn. 2007;236:1072-84. doi:10.1002/dvdy.21095

[38] Piotrowski T, Nüsslein-Volhard C. The endoderm plays an important role in patterning the segmented pharyngeal region in zebrafish (Danio rerio). Dev Biol. 2000;225:339-56. doi:10.1006/dbio.2000.9842

[39] Narboux-Neme N, Pavone LM, Avallone L, Zhuang X, Gaspar P. Serotonin transporter transgenic (SERTcre) mouse line reveals developmental targets of serotonin specific reuptake inhibitors (SSRIs). Neuropharmacology. 2008;55:994-1005. doi:10.1016/j. neuropharm.2008.08.020.

[40] Shuey DL, Sadler TW, Lauder JM. Serotonin as a regulator of craniofacial morphogenesis: site specific malformations following exposure to serotonin uptake inhibitors. Teratology. 1992;46:367-78. doi:10.1002/tera.1420460407

[41] Shuey DL, Sadler TW, Tamir H, Lauder JM. Serotonin and morphogenesis. Transient expression of serotonin uptake and binding protein during craniofacial morphogenesis in the mouse. Anat Embryol (Berl). 1993;187:75-85. doi:10.1007/BF0020 8198

[42] Hansson SR, Mezey E, Hoffman BJ. Ontogeny of vesicular monoamine transporter mRNAs VMAT1 and VMAT2. II. Expression in neural crest derivatives and their target sites in the rat. Brain Res Dev Brain Res. 1998;110:159-74. doi:10.1016/S0165-3806 (98)00103-5

[43] Vitalis T, Alvarez C, Chen K, Shih JC, Gaspar P, Cases O. Developmental expression pattern of monoamine oxidases in sensory organs and neural crest derivatives. J Comp Neurol. 2003;464:392-403. doi:10.1002/cne.10804

[44] Blackiston D, Adams DS, Lemire JM, Lobikin M, Levin M. Transmembrane potential of GlyCl-expressing instructor cells induces a neoplastic-like conversion of melanocytes via a serotonergic pathway. Dis Model Mech. 2011;4:67-85. doi:10.1242/ dmm.005561.

[45] Kapsimali M, Kaushik AL, Gibon G, Dirian L, Ernest S, Rosa FM. Fgf signaling controls pharyngeal taste bud formation through miR-200 and Delta-Notch activity. Development. 2011;138: 3473-84. doi:10.1242/dev.058669

[46] Zachar PC, Jonz MG. Confocal imaging of Merkel-like basal cells in the taste buds of zebrafish. Acta Histochem. 2012;114:10115. doi:10.1016/j.acthis.2011.03.006.
[47] Alenina N, Kikic D, Todiras M, Mosienko V, Qadri F, Plehm R, Boye P, Vilianovitch L, Sohr R, Tenner K, Hortnagl H, Bader M. Growth retardation and altered autonomic control in mice lacking brain serotonin. Proc Natl Acad Sci USA. 2009;106:10332-7. doi:10.1073/pnas.0810793106

[48] Bonnin A, Goeden N, Chen K, Wilson ML, King J, Shih JC, Blakely RD, Deneris ES, Levitt P. A transient placental source of serotonin for the fetal forebrain. Nature. 2011;472:347-50. doi:10.1038/nature09972

[49] Cote F, Fligny C, Bayard E, Launay JM, Gershon MD, Mallet J, Vodjdani G. Maternal serotonin is crucial for murine embryonic development. Proc Natl Acad Sci USA. 2007;104:329-34. doi:10.1073/pnas.0606722104

[50] Launay JM, Schneider B, Loric S, Da Prada M, Kellermann O. Serotonin transport and serotonin transporter-mediated antidepressant recognition are controlled by 5-HT2B receptor signaling in serotonergic neuronal cells. Faseb J. 2006;20:1843-54. doi:10.1096/fj.06-5724com

[51] Nebigil CG, Choi DS, Dierich A, Hickel P, Le Meur M, Messaddeq N, Launay J-M, Maroteaux L. Serotonin 2B receptor is required for heart development. Proc Natl Acad Sci USA. 2000;97:950813. doi:10.1073/pnas.97.17.9508

[52] Ori M, De Lucchini S, Marras G, Nardi I. Unraveling new roles for serotonin receptor $2 \mathrm{~B}$ in development: key findings from Xenopus. Int J Dev Biol. 2013;57:707-14. doi:10.1387/ijdb. $130204 \mathrm{mo}$.

[53] Cornide-Petronio ME, Anadon R, Rodicio MC, Barreiro-Iglesias A. The sea lamprey tryptophan hydroxylase: new insight into the evolution of the serotonergic system of vertebrates. Brain Struct Funct. 2012;218:587-93. doi:10.1007/s00429-0120412-7.

[54] Carrera I, Molist P, Anadon R, Rodriguez-Moldes I. Development of the serotoninergic system in the central nervous system of a shark, the lesser spotted dogfish Scyliorhinus canicula. J Comp Neurol. 2008;511:804-31. doi:10.1002/cne.21857.

\section{COMPETING INTERESTS}

The authors declare no competing interests.

\section{PUBLISHING NOTES}

(C) 2014 S. Bashammakh et al. This work has been published open access under Creative Commons Attribution License CC BY 4.0, which permits unrestricted use, distribution, and reproduction in any medium, provided the original work is properly cited. Conditions, terms of use and publishing policy can be found at www.scienceopen.com.

Please note that this article may not have been peer reviewed yet and is under continuous post-publication peer review. For the current reviewing status please click here or scan the QR code on the right.

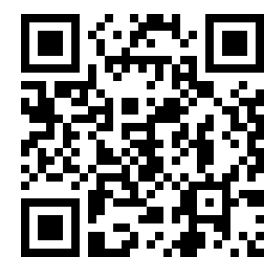

\section{scienceOPEN.com}

